\title{
Perceptual and cognitive effects of antipsychotics in first-episode schizophrenia: The potential impact of GABA concentration in the visual cortex
}

\author{
Oguz Kelemen ${ }^{\text {a }}$, Imre Kiss ${ }^{\text {b }}$, György Benedek ${ }^{\mathrm{c}}$, Szabolcs Kéri b,c,d,* \\ a Bács-Kiskun County Hospital, Psychiatry Center, Kecskemét, Hungary \\ b Gyula Nyírö Hospital, National Institute of Psychiatry and Addictions, Budapest, Hungary \\ c University of Szeged, Faculty of Medicine, Department of Physiology, Szeged, Hungary \\ d Budapest University of Technology and Economics, Department of Cognitive Science, Budapest, Hungary
}

\section{A R T I C L E I N F O}

\section{Article history:}

Received 23 May 2013

Received in revised form 16 July 2013

Accepted 31 July 2013

Available online 13 August 2013

\section{Keywords:}

Antipsychotics

Cognition

Contrast sensitivity

Motion perception

Schizophrenia

Vision

\begin{abstract}
A B S T R A C T
Schizophrenia is characterized by anomalous perceptual experiences (e.g., sensory irritation, inundation, and flooding) and specific alterations in visual perception. We aimed to investigate the effects of short-term antipsychotic medication on these perceptual alterations. We assessed 28 drug-naïve first episode patients with schizophrenia and 20 matched healthy controls at baseline and follow-up 8 weeks later. Contrast sensitivity was measured with steady- and pulsed-pedestal tests. Participants also received a motion coherence task, the Structured Interview for Assessing Perceptual Anomalies (SIAPA), and the Repeatable Battery for the Assessment of Neuropsychological Status (RBANS). Proton magnetic resonance spectroscopy was used to measure gammaaminobutyric acid (GABA) levels in the occipital cortex (GABA/total creatine [Cr] ratio). Results revealed that, comparing baseline and follow-up values, patients with schizophrenia exhibited a marked sensitivity reduction on the steady-pedestal test at low spatial frequency. Anomalous perceptual experiences were also significantly ameliorated. Antipsychotic medications had no effect on motion perception. RBANS scores showed mild improvements. At baseline, but not at follow-up, patients with schizophrenia outperformed controls on the steady-pedestal test at low spatial frequency. The dysfunction of motion perception (higher coherence threshold in patients relative to controls) was similar at both assessments. There were reduced GABA levels in schizophrenia at both assessments, which were not related to perceptual functions. These results suggest that antipsychotics dominantly affect visual contrast sensitivity and anomalous perceptual experiences. The prominent dampening effect on low spatial frequency in the steady-pedestal test might indicate the normalization of putatively overactive magnocellular retino-geniculo-cortical pathways.
\end{abstract}

C 2013 Elsevier Inc. All rights reserved.

\section{Introduction}

Patients with schizophrenia often report anomalous perceptual experiences that are subjectively and phenomenologically different from hallucinations and other positive psychotic symptoms. These experiences include disturbingly high intensity of environmental stimuli, feelings of being flooded and inundated, and inability to focus attention to relevant details (Bunney et al., 1999; Klosterkötter et al., 2001; Phillipson and Harris, 1985), which is most prevalent and severe in

\footnotetext{
Abbreviations: ANOVA, analysis of variance; c/d, cycles/degree; $\mathrm{Cr}$, creatine; GABA, gamma-aminobutyric acid; HSD, honestly significant difference; M, magnocellular; P, parvocellular; PANSS, Positive and Negative Syndrome Scale; RBANS, Repeatable Battery for the Assessment of Neuropsychological Status; SIAPA, Structured Interview for Assessing Perceptual Anomalies.

* Corresponding author at: University of Szeged, Faculty of Medicine, Department of Physiology, Szeged, Hungary. Tel.: + 36204483530 .

E-mail addresses: szkeri2000@yahoo.com, keri.szabolcs.gyula@med.u-szeged.hu (S. Kéri).
}

the auditory and visual sensory modalities (Bunney et al., 1999; Martín-Reyes et al., 2010; Mendoza Quiñones et al., 2007).

In a series of studies, we explored the possible psychophysical correlates of anomalous perceptual experiences, with a special reference to the visual modality (Kéri et al., 2005; Kiss et al., 2010). Initially, we used the framework of the retino-geniculo-cortical magnocellular (M) and parvocellular $(\mathrm{P})$ visual pathways, which originate in the retina and are theoretically responsible for the processing of different kinds of stimulus features (M pathways: low spatial frequencies [rough resolution of objects], luminance contrast, motion; P pathways: high spatial frequencies [fine resolution of objects], color contrast, form) (Nassi and Callaway, 2009). However, despite the fact that this perceptual hypothesis received an extensive attention in the literature of schizophrenia (e.g., reviewed by Butler et al., 2008; Javitt, 2009), the exact psychophysical distinction of $\mathrm{M}$ and $\mathrm{P}$ pathways has been debated (Goodbourn et al., 2012; Merigan and Maunsell, 1993; Skottun and Skoyles, 2007).

During past decades of research, Pokorny and colleagues developed a new method for the separation of putative $\mathrm{M}$ and $\mathrm{P}$ pathways, which 
became popular in clinical research (reviewed by Pokorny, 2011). In the pulsed-pedestal paradigm, the target detection period, during which participants are requested to detect a briefly flashed low-contrast grating, is preceded by an adaptation period containing a homogeneous high luminance field. During the target detection period, the luminance of the background field is abruptly reduced, which saturates $M$ pathways, but not P pathways. Therefore, the pulsed-pedestal paradigm shifts information processing toward the P pathways. In the steadypedestal condition, M pathways are not saturated and therefore briefly presented stimuli with low contrast and low spatial frequency are thought to be dominantly processed by these pathways (Fig. 1; for a critical review and comparison with other methods, see Skottun and Skoyles, 2011).

Using the steady-/pulsed-pedestal tasks in drug-naïve first-episode schizophrenia patients, Kiss et al. (2010) found abnormally heightened sensitivity for putatively M-biased stimuli, indicating an overactive visual response. A similar finding was reported by Antal et al. (1998) and Chen et al. (2003) using conventional contrast sensitivity measurements. Critically, higher M-biased contrast sensitivity values were associated with increased scores on a standardized scale for anomalous perceptual experiences (Kiss et al., 2010).

The primary purpose of the present study was to investigate the effect of short-term antipsychotic medication on visual contrast sensitivity and anomalous perceptual experiences in first-episode schizophrenia. Given that, by the inhibition of dopamine $\mathrm{D}_{2}$ receptors in the retina, antipsychotics have a profound effect on contrast processing (Bulens et al., 1989; Harris et al., 1990; Kéri et al., 2002), we hypothesized rapidly dampened contrast sensitivity and, if it is indeed related to anomalous perceptual experiences, a parallel amelioration of subjective sensory symptoms. Second, we assessed higher levels of visual processing, that is, the perception of coherent motion. Extensive evidence suggests that motion perception is impaired in schizophrenia and that it is related to higher levels of cortical information processing (area MT/V5) (Chen, 2011). However, the effect of antipsychotic medications on motion processing has not been clarified. Third, we administered a battery of neuropsychological tests to tackle changes in neurocognition (attention, memory, visual-spatial processing, and language) during therapy. Past studies revealed a mild beneficial effect of antipsychotics on neurocognition (for meta-analyses, see Woodward et al., 2005, 2007). Finally, we measured gamma-aminobutyric acid (GABA) concentration in the occipital cortex before and after antipsychotic therapy and compared that with perceptual changes. This final aim of the study was based on the findings of Yoon et al. (2010) who identified a strong positive correlation between occipital GABA concentration and visual inhibition (orientation-specific surround suppression). These authors hypothesized that decreased GABA concentration in the visual cortex of patients with schizophrenia caused weakened visual inhibition (Yoon et al., 2010).

\section{Material and methods}

\subsection{Participants}

Twenty-eight patients with first-episode schizophrenia and twenty healthy control volunteers participated in the study. Some of the participants have been included in previous studies where details of recruitment have been described (Kéri et al., 2010; Kiss et al., 2010; Szamosi et al., 2012). There were two recruitment centers in Southern Hungary and Budapest. Patients were referred from the whole country. None of the patients received previous treatment with psychotropic medications, and they were therefore drug-naïve at the time of baseline assessment. The mean duration of untreated psychosis was 9.7 months $(S D=6.1)$. All participants received the Structured Clinical Interview for DSM-IV Axis I Disorders, Clinician Version (SCID-CV) (First et al., 1996). We used the Positive and Negative Syndrome Scale (PANSS) for the evaluation of clinical symptoms (Kay et al., 1987). Exclusion criteria included neurological disorders, head injury, and history of psychoactive substance misuse. All participants had normal or correctedto-normal visual acuity. The clinical and demographic characteristics are depicted in Table 1 . The study was carried out in accordance with the Declaration of Helsinki and was approved by the local ethics board. After a full description of the study, participants gave written informed consent.

\subsection{Medications}

We first assessed the patients in a drug-naïve state (baseline). This baseline assessment was followed by 8 weeks of treatment. The dose and type of antipsychotic medications administered to patients were at the discretion of the treating physician who was blind to the aims of the study. All clinical scales and tests were administered by trained and supervised clinical psychologists and psychiatrist who were blind to the medication status of the patients. Patients received the following medications: haloperidol ( $\mathrm{n}=1,4 \mathrm{mg} /$ day); olanzapine ( $\mathrm{n}=10$,

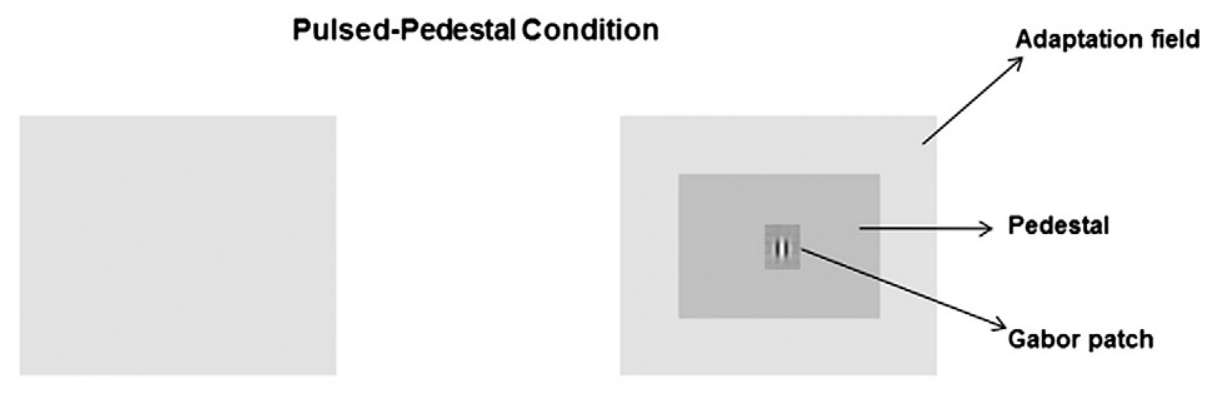

Steady-Pedestal Condition
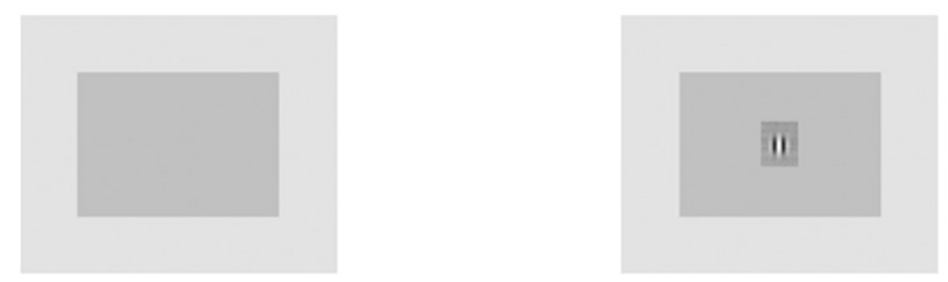

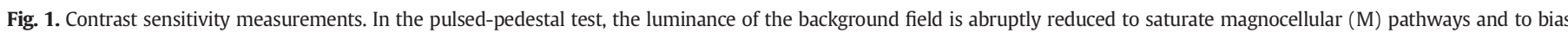
information processing toward the parvocellular $(\mathrm{P})$ pathways. In the steady-pedestal paradigm, the luminance of the background field is constant. 
Table 1

Clinical and demographic characteristics of the participants.

\begin{tabular}{lll}
\hline & $\begin{array}{l}\text { Schizophrenia } \\
(\mathrm{n}=28)\end{array}$ & $\begin{array}{l}\text { Control } \\
(\mathrm{n}=20)\end{array}$ \\
\hline Gender (male/female) & $18 / 10$ & $14 / 6$ \\
Age (years) & $24.9(8.3)$ & $24.2(6.9)$ \\
Education (years) & $11.0(3.9)$ & $11.3(3.6)$ \\
Positive and Negative & & \\
$\quad$ Syndrome Scale (PANSS) & & \\
$\quad$ Positive & & - \\
$\quad$ Baseline & $18.4(7.6)$ & - \\
$\quad$ Follow-up & $11.2(3.4)$ & - \\
$\quad$ Negative & $13.4(6.9)$ & - \\
$\quad$ Baseline & $9.9(6.2)$ & - \\
$\quad$ Follow-up & & \\
General & $56.4(16.4)$ & \\
$\quad$ Baseline & $45.8(12.3)$ & \\
$\quad$ Follow-up & & \\
Structured Interview for & & \\
$\quad$ Assessing Perceptual Anomalies (SIAPA) - & \\
$\quad$ Visual Domain & & \\
$\quad$ Baseline & $2.16(1.5)$ & \\
$\quad$ Follow-up & $0.38(0.8)$ &
\end{tabular}

Data are mean (standard deviation). Statistical details are presented in the main text.

a Significant reduction in scores (follow-up relative to baseline)

dose: $10-25 \mathrm{mg} /$ day); quetiapine ( $\mathrm{n}=4 ; 200-800 \mathrm{mg} /$ day); risperidone ( $\mathrm{n}=11$, dose: $2-6 \mathrm{mg} /$ day); zuclopenthixol ( $\mathrm{n}=2 ; 25 \mathrm{mg} /$ day). Mood stabilizers (valproate, $\mathrm{n}=5$ ), benzodiazepines (alprazolam or clonazepam, $\mathrm{n}=16$ ), and anticholinergics (biperiden, $\mathrm{n}=5$ ) were allowed during the treatment period.

\subsection{Anomalous perceptual experiences}

We used the Structured Interview for Assessing Perceptual Anomalies (SIAPA) for the assessment of subjective anomalous perceptual experiences (Bunney et al., 1999). The SIAPA separately evaluates sensory intensity, inundation or flooding, and selective attention to external stimuli in the five sensory modalities using a 0 (never occurred)-5 (always present) scale. For example, in the visual modality, participants rate whether lights seem much brighter, the intensity of colors is greater (i.e., more vivid), complex visual environments are bothersome, and he or she is overwhelmed by multiple visual stimuli and cannot attend to one of many simultaneous visual inputs (Bunney et al., 1999). In the present study, we focused on the visual modality. Two independent raters assessed each patient (kappa > 0.7).

\subsection{Visual contrast sensitivity}

The method of contrast sensitivity measurements was described in details in previous publications (Alexander et al., 2005; Kiss et al., 2010; Leonova et al., 2003; Pokorny and Smith, 1997). We used a gamma-corrected ViewSonic PF815 monitor controlled by an IBM-compatible PC. Stimuli were Gabor patches (size: $2.5^{\circ} \times 2.5^{\circ}$ ) with a luminance-contrast profile formed by the multiplication of a sinusoidal waveform with a Gaussian envelope (Fig. 1). Participants were asked to detect of a briefly flashed low-contrast Gabor patch (exposure time: $45 \mathrm{~ms}$ ). The patch was presented in the center of a square luminance pedestal $\left(7.6^{\circ}\right.$ on a side, mean luminance: $\left.12 \mathrm{~cd} / \mathrm{m}^{2}\right)$. The pedestal was localized in the center of a homogeneous adapting field $\left(12.0^{\circ}\right.$ on a side, mean luminance: $25 \mathrm{~cd} / \mathrm{m}^{2}$ ), producing a luminance decrement (Fig. 1).

In the steady-pedestal paradigm, the pedestal was presented continuously, whereas in the pulsed-pedestal paradigm, the pedestal was exposed only during the test period, together with the target Gabor patch. In both paradigms, we used a 30-s adaptation period before the test period.
An experimental trial was initiated by the participant when he or she pressed the space bar on the computer keyboard, which was followed by a warning tone immediately preceding the presentation of the target patch. We asked the participants to judge whether the patch was horizontal or vertical (key "1" for vertical and key "0" for horizontal). The participants gave oral responses, which were entered by the experimenter. The order of steady- and pulsed-pedestal conditions was randomized. In each condition, contrast thresholds were measured at 2 spatial frequencies ( 0.25 and 4 cycles/degree [c/d]) using an adaptive staircase method. We used only 2 spatial frequencies in order to shorten the duration of the testing session.

The staircase steps were calculated as follows (Treutwein, 1995):

$X_{n+1}=X_{n}-c /\left(2+m_{\text {shift }}\right)\left(Z_{n}-\phi\right)$

$\begin{array}{ll}X_{n} & \text { step size on trial } n \\ c & \text { initial contrast value (40\%) } \\ m_{\text {shift }} & \text { cumulative number of reversals } \\ Z_{n} & \text { observer's response }(0 \text { or } 1) \\ \phi & \text { targeted percent correct value (80\%) }\end{array}$

The staircase was terminated after the 12th reversal. The contrast threshold was the average of the final 6 reversals. Contrast sensitivity was the inverse of the contrast threshold.

\subsection{Motion perception}

We used Glass pattern stimuli to determine motion coherence threshold (Glass, 1969; Kéri and Benedek, 2012; McKendrick et al., 2006) (Fig. 2). During the measurement, a fraction of randomly chosen dots moved in the same signal direction, whereas the remaining dots did not move coherently ( $9 \mathrm{~min}$ arc/frame, $3 \mathrm{deg} / \mathrm{s}$ ). We measured coherence thresholds (percentage of coherently moving dots necessary for stimulus detection) using a staircase procedure.

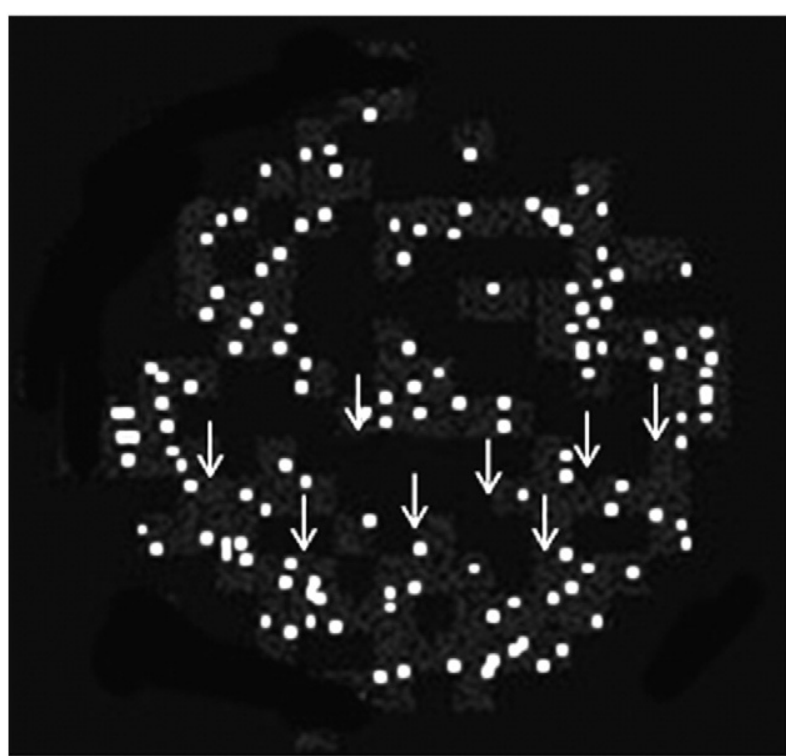

Fig. 2. Motion coherence. A percentage of dots are moving downward as illustrated by white arrows. The remainder of dots moves in random directions. 


\subsection{Neurocognition}

Volunteers completed the RBANS battery, which includes 12 neuropsychological tests classified according to 5 index scores (Gold et al., 1999; Juhász et al., 2003; Randolph et al., 1998). Each index score is standardized (mean: $100, S D=15$ based on a normative study group of 200 healthy Hungarian volunteers, 20-80 years of age). The 5 RBANS index domains are as follows: (1) immediate memory (word list learning [ 10 words repeated in four trials], story recall in two trials); (2) language (confrontation naming of 10 pictures, category fluency); (3) visuospatial functions (figure copy, line orientation); (4) attention (digit span, digit-symbol coding); (5) delayed memory (delayed recall of the story, complex figure, and word list, recognition of the word list). The RBANS battery has two psychometrically matched forms, "A" and "B", providing an opportunity to avoid practice effects by repeating the same tests twice. We report the overall RBANS score (average of the 5 domain scores) to increase statistical power.

\subsection{Spectroscopic measurements}

We measured GABA with proton magnetic resonance spectroscopy (MRS) using a Siemens Trio 3 T scanner. We used the scanning parameters and MRS protocol of Yoon et al. (2010). The scanning parameters were as follows: repetition time, $1500 \mathrm{~ms}$; echo time, $68 \mathrm{~ms}$; edit frequency $1.9 \mathrm{ppm}$; delta frequency, -1.7 ; edit pulse bandwidth, $45 \mathrm{~Hz}$; number of excitations, 256; and scan duration, $6.5 \mathrm{~min}$. We placed paired surface coils under the occiput. The region-of-interest was a $35 \times 30 \times 25 \mathrm{~mm}$ voxel centered on the calcarine sulcus (posterior border: $7 \mathrm{~mm}$ anterior the dura mater). The method of Mescher et al. (1998) was the basis of the measurement of total GABA, as used by Yoon et al. (2010). The ratio of total GABA/total creatine ( $\mathrm{Cr}$ ) signal from the occipital cortex was the dependent measure.

\subsection{Statistical analysis}

We used STATISTICA 11 (StatSoft, Inc., Tulsa) software. All statistical tests were designed before the experiment. After the quality analysis of data (Kolmogorov-Smirnov and Levene's tests), measures were entered into analyses of variance (ANOVA). Tukey Honestly Significant Difference (HSD) tests were used for post-hoc comparisons. Clinical scale scores were compared with two-tailed t-tests. Cohen's effect size values $(d)$ were calculated to characterize differences in RBANS scores. We used Pearson's product moment correlation coefficients to determine the relationship between psychophysical data and GABA levels. The level of statistical significance was set at $\alpha<0.05$.

\section{Results}

\subsection{SIAPA and PANSS scores}

Table 1 shows the SIAPA and PANSS scores at baseline and follow-up. Patients with schizophrenia displayed significant improvements in PANSS scores (positive: $\mathrm{t}(54)=4.49, \mathrm{p}<0.001$; negative: $\mathrm{t}(54)=2.0$, $\mathrm{p}=0.05$; general: $\mathrm{t}(54)=2.75, \mathrm{p}<0.05)$. We also observed a significant reduction in SIAPA scores $(\mathrm{t}(54)=5.83, \mathrm{p}<0.0001)$.

\subsection{Contrast sensitivity}

The ANOVA conducted on the contrast sensitivity data had the following design: group (schizophrenia vs. controls) by time (baseline vs. follow-up) by stimulus type (steady- vs. pulsed -pedestal) by SF $(0.25 \mathrm{c} / \mathrm{d}$ vs. $4 \mathrm{c} / \mathrm{d})$. The results are summarized in Table 2 . We focused the post hoc analysis on two key issues: (i) differences between patients and controls at baseline and follow-up; (ii) the characteristics of this possible difference regarding stimulus type and spatial frequency. The only significant difference was found at $0.25 \mathrm{c} / \mathrm{d}$ in the steady-pedestal
Table 2

Results from the ANOVA conducted on the contrast sensitivity data.

\begin{tabular}{lrcl}
\hline & $F$ & $p$ & $\eta^{2}$ \\
\hline Main effects & & & \\
Group (1) & 0.03 & 0.85 & 0.0 \\
Time (2) & 62.08 & $<0.0001$ & 0.57 \\
Stimulus (3) & 96.65 & $<0.0001$ & 0.68 \\
Spatial frequency (4) & 39.63 & $<0.0001$ & 0.46 \\
Interactions & & & \\
$1 \times 2$ & 52.65 & $<0.0001$ & 0.53 \\
$1 \times 3$ & 8.44 & 0.01 & 0.16 \\
$1 \times 4$ & 0.18 & 0.68 & 0.0 \\
$2 \times 3$ & 26.19 & $<0.0001$ & 0.36 \\
$2 \times 4$ & 9.22 & 0.004 & 0.17 \\
$3 \times 4$ & 168.15 & $<0.0001$ & 0.79 \\
$1 \times 2 \times 3$ & 28.79 & $<0.0001$ & 0.38 \\
$1 \times 2 \times 4$ & 19.50 & $<0.001$ & 0.29 \\
$1 \times 3 \times 4$ & 1.47 & 0.23 & 0.03 \\
$2 \times 3 \times 4$ & 13.42 & 0.0006 & 0.23 \\
$1 \times 2 \times 3 \times 4$ & 10.1 & 0.003 & 0.18 \\
\hline
\end{tabular}

$\mathrm{df}=1,46$; group: schizophrenia vs. control; time: baseline vs. follow-up; stimulus: steady- vs. pulsed-pedestal; spatial frequency: $0.25 \mathrm{c} / \mathrm{d}$ vs. $4 \mathrm{c} / \mathrm{d}$.

condition in the baseline assessment: patients with schizophrenia showed significantly higher sensitivity compared to control individuals $(p=0.0002)$. There were no other between-group differences at baseline $(p>0.5)$. Similarly, at follow-up, patients and controls performed similarly in all conditions ( $\mathrm{p}>0.5$ ) (Fig. 3 ).

When we investigated within-group changes in contrast sensitivity (baseline vs. follow-up), a marked stability was revealed in controls $(p>0.5)$. In patients with schizophrenia, however, there were significantly reduced contrast sensitivity values in the steady-pedestal condition at both spatial frequencies ( $\mathrm{p}=0.0002$ ) (Fig. 3).

\subsection{Motion perception}

Coherence values are depicted in Table 3. The ANOVA yielded a significant main effect of group $\left(F(1,46)=7.89, p<0.05, \eta^{2}=0.16\right)$. The main effect of time and the interaction between group and time were not significant $(\mathrm{p}>0.1)$. Patients with schizophrenia displayed higher coherence threshold values compared to control individuals at baseline and follow-up ( $\mathrm{p}=0.007)$.

\subsection{Neurocognition}

RBANS composite scores are depicted in Table 3. We found significant main effects of group $\left(F(1,46)=6.96, p<0.05, \eta^{2}=0.13\right)$ and time $\left(\mathrm{F}(1,46)=10.74, \mathrm{p}<0.01, \eta^{2}=0.19\right)$. The interaction between group and time was significant $\left(F(1,46)=11.89, \mathrm{p}<0.04, \eta^{2}=0.20\right)$. Tukey HSD tests revealed that patients with schizophrenia exhibited a significant cognitive deficit at baseline $(p=0.01)$, but not at follow-up ( $p>0.1)$. At baseline, the effect size was $d=0.85$, whereas at followup it was $d=0.57$, with a $d=0.28$ improvement in patients with schizophrenia (Tukey HSD, $\mathrm{p}<0.01$ ).

\subsection{GABA level and its relationship with visual functions}

The ANOVA revealed a significant main effect of group $(F(1,46)=$ $6.68, \mathrm{p}<0.05, \eta^{2}=0.13$ ), but the main effect of time and the twoway interaction were not significant $(\mathrm{p}>0.1)$. Patients with schizophrenia displayed lower $\mathrm{GABA} / \mathrm{Cr}$ ratio relative to control individuals at baseline and follow-up ( $<<0.05)$ (Table 3$)$. There were no significant correlations between $\mathrm{GABA} / \mathrm{Cr}$ ratio and visual contrast sensitivity $(-0.1<\mathrm{r}<0.1, \mathrm{p}>0.5)$. 

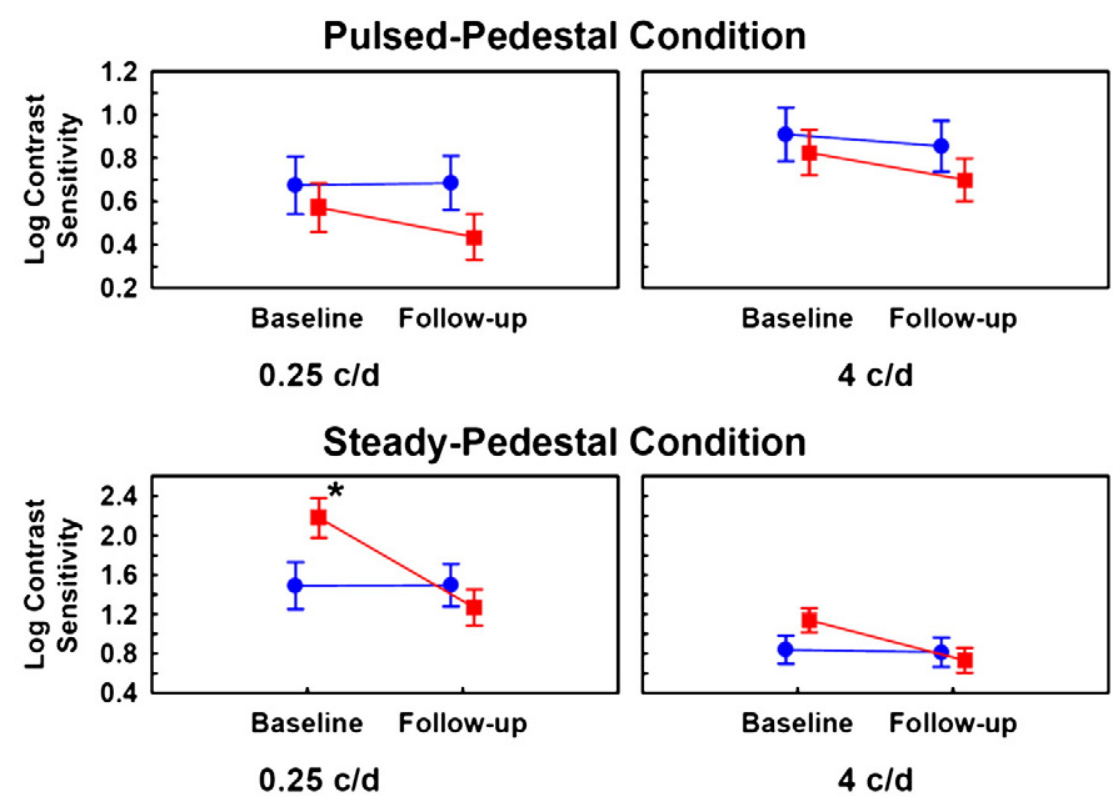

CONT $(n=20)$

$\operatorname{SCH}(n=28)$

Fig. 3. Contrast sensitivity results. Data are mean (error bars: $95 \%$ confidence intervals). CONT - controls, $\mathrm{SCH}-\mathrm{schizophrenia.}{ }^{*} \mathrm{p}<0.001$, SCH $>$ CONT.

\section{Discussion}

The results of the present study indicated that short-term antipsychotic treatment had a robust effect on early-stage visual functions and anomalous perceptual experiences: there was a significant reduction of contrast hypersensitivity in schizophrenia, together with the amelioration of anomalous perceptual experiences. Interestingly, higher-level motion processing was not affected during the antipsychotic treatment, which suggests that the underlying mechanism of its impairment is at least partly different from early-stage contrast perception. Finally, consistent with past studies, we observed a modest improvement in neurocognitive functions (Woodward et al., 2005, 2007).

Recent models emphasize the interaction between GABA-ergic interneurons and glutamatergic neurotransmission in the pathophysiology of schizophrenia (Gonzalez-Burgos and Lewis, 2012), possibly modulated by dopaminergic mechanisms (Benes, 1997). We expected that visual functions, anomalous perceptual experiences and their changes during the treatment would be related to GABA levels in the

Table 3

Motion perception, neurocognition, and GABA concentration.

\begin{tabular}{lcl}
\hline & \multicolumn{1}{c}{ Schizophrenia $(\mathrm{n}=28)$} & Controls $(\mathrm{n}=20)$ \\
\hline $\begin{array}{l}\text { Motion coherence threshold }(\%)^{a} \\
\text { Baseline }\end{array}$ & $34.9(8.1)$ & $28.2(8.2)$ \\
Follow-up & $35.6(8.5)$ & $29.2(7.7)$ \\
RBANS $^{b}$ & & \\
Baseline & $85.5(11.2)$ & $95.4(10.5)$ \\
Follow-up & $89.6(8.4)$ & $95.3(10.8)$ \\
GABA/Cr & & \\
Baseline & & $0.11(0.03)$ \\
Follow-up & $0.08(0.05)$ & $0.11(0.03)$ \\
\hline
\end{tabular}

Data are mean (standard deviation).

a Patients showed higher thresholds at both baseline and follow-up relative to control individuals (Tukey HSD, $\mathrm{p}<0.05$ ).

b Patients showed lower RBANS (Repeatable Battery for the Assessment of Neuropsychological Status) scores relative to control individuals at baseline, which showed a significant improvement at follow-up (Tukey HSD, $\mathrm{p}<0.01$ ).

${ }^{c}$ There were reduced GABA/Cr values in patients compared to control individuals at both baseline and follow-up (Tukey HSD, $\mathrm{p}<0.05$ ) (for statistical details, see text). occipital cortex (Yoon et al., 2010). However, the data did not support this hypothesis. The GABA level showed a definitive stability during the treatment, which is in accordance with the results of Goto et al. (2010) (but see Kegeles et al., 2012; Ongür et al., 2010; Tayoshi et al., 2010; reviewed by Szulc et al., 2013). Yoon et al. (2010) showed that GABA concentration correlated with visual inhibition only when stimuli consisting of multiple components were used (e.g., a center grating to detect and a modulating surround) and there was an inhibitory interaction among these components (orientation-specific surround suppression). When there was no surround, contrast perception for isolated gratings did not depend on GABA concentration, probably because interactions between inhibitory synaptic connections were not involved (Yoon et al., 2010). Rokem et al. (2011) demonstrated that stimulus orientation tuning was altered in early visual cortex in schizophrenia and this tuning function was related to GABA level.

The modulatory effect of antipsychotics on contrast perception may be distinct from cortical GABA-ergic mechanisms. Several lines of evidence suggest that the inhibition of dopamine receptors in the retina affects contrast processing (Bodis-Wollner, 1990). This precortical mechanism may be responsible for the effect we observed, although this study did not investigate this hypothesis directly.

A critical issue is whether early-stage visual functions are modulated by the natural course of the illness regardless the application of antipsychotic medications. We observed contrast hypersensitivity in individuals at clinical high risk for psychosis (Kéri and Benedek., 2007), but not in chronic patients (Kéri et al., 2002). In chronic patients, contrast sensitivity was related not only to antipsychotic dose (Kéri et al., 2002), but also to negative symptoms (Slaghuis, 1998). Similarly, dysfunctions of attention may interfere with contrast processing (Kéri et al., 1999). Preliminary evidence from chronic patients with schizophrenia who did not receive antipsychotics at least for 4 weeks suggests decreased contrast sensitivity relative to controls (unpublished observation), although the long-term effects of previously applied antipsychotics cannot be excluded. Another methodological confound may be hidden ophthalmological alterations in chronic patients, often suffering from a poor general medical condition.

The possible differential effect of disease stage and medication status on cortical GABA concentrations also needs further investigation because the results are not conclusive. In the Yoon et al. (2010) study, 
demonstrating decreased occipital GABA concentration, a mixture of chronic and recent onset patients with schizophrenia was included. In contrast, Ongür et al. (2010) demonstrated elevations in GABA in the parieto-occipital cortex of patients with chronic schizophrenia. Finally, Kegeles et al. (2012) reported elevations in GABA levels in the medial prefrontal cortex but not the dorsolateral prefrontal cortex of unmedicated patients (mean duration of illness: 7 years), whereas medicated patients (mean duration of illness: 9 years) did not display elevated GABA levels.

The finding that contrast hypersensitivity and the effect of antipsychotics were the most pronounced in the steady-pedestal condition at low spatial frequency suggests the pivotal role of putative M pathways, which may be implicated in the development of anomalous perceptual experiences (Kéri et al., 2005; Kiss et al., 2010). The overactivity of M pathways (transient channels) was also raised in the backward masking literature of schizophrenia (Green et al., 1994). This hypothesis should be confirmed by the direct visualization of $\mathrm{M}$ and $\mathrm{P}$ pathways at the precortical level. However, the relationship between altered general perceptual processing and the classic clinical symptoms of schizophrenia is still controversial. Javitt (2009) postulated that basic perceptual processes, localized to precortical channels and primary sensory regions of the cortex, are responsible for bottom-up deficits in cognitive processing. In the visual system, for example, M pathway impairments may result in higher-order deficits in perceptual organization (i.e., assembling parts into whole objects), object recognition, processing of facial expressions, and reading (Javitt, 2009). These may be related to negative symptoms and social dysfunctions. Anomalous visual perceptual experiences, on the other hand, are prevalent in the early phase of the illness (Klosterkötter et al., 2001), and, as shown by the present study, display a rapid response to antipsychotic treatment.

The most important aim of future research is to explore the relevance of these findings in terms of everyday clinical practice. A comprehensive assessment is necessary to reveal the usefulness of the investigation of anomalous perceptual experiences and related psychophysical mechanisms in the early recognition of schizophrenia and in the monitoring of therapeutic response.

\section{Acknowledgments}

This study was supported by the National Development Agency (TÁMOP-4.2.2.A-11/1/KONV-2012-0052).

\section{References}

Alexander KR, Barnes CS, Fishman GA, Pokorny J, Smith VC. Contrast sensitivity deficits in inferred magnocellular and parvocellular pathways in retinitis pigmentosa. Invest Ophthalmol Vis Sci 2005;45:4510-9.

Antal A, Kéri Sz, Szekeres Gy, Szendi I, Kovács Z, Benedek Gy, et al. A szenzoros gátlási folyamatok zavara szkizofréniában I. A magnocelluláris pálya szelektív hiperaktivitása. Psychiatr Hung 1998:13:679-84. [Article in Hungarian].

Benes FM. The role of stress and dopamine-GABA interactions in the vulnerability for schizophrenia. J Psychiatr Res 1997;31:257-75

Bodis-Wollner I. Visual deficits related to dopamine deficiency in experimental animals and Parkinson's disease patients. Trends Neurosci 1990;13:296-302.

Bulens C, Meerwaldt JD, van der Wildt GJ, Keemink CJ. Visual contrast sensitivity in drug-induced Parkinsonism. J Neurol Neurosurg Psychiatry 1989;52:341-5.

Bunney WE, Jr, Hetrick WP, Bunney BG, Patterson JV, Jin Y, Potkin SG, et al. Structured interview for assessing perceptual anomalies (SIAPA). Schizophr Bull 1999;25:577-92.

Butler PD, Silverstein SM, Dakin SC. Visual perception and its impairment in schizophrenia. Biol Psychiatry 2008;64:40-7.

Chen Y. Abnormal visual motion processing in schizophrenia: a review of research progress. Schizophr Bull 2011;37:709-15.

Chen Y, Levy DL, Sheremata S, Nakayama K, Matthysse S, Holzman PS. Effects of typical, atypical, and no antipsychotic drugs on visual contrast detection in schizophrenia. Am J Psychiatry 2003;160:1795-801.

First MB, Spitzer RL, Gibbon M, Williams JBW. Structured clinical interview for DSM-IV axis I disorders, clinician version (SCID-CV). Washington, DC: American Psychiatric Press; 1996.

Glass L. The Moire effect from random dots. Nature 1969;223:578-80.

Gold JM, Queern C, Iannone VN, Buchanan RW. Repeatable battery for the assessment of neuropsychological status as a screening test in schizophrenia I: sensitivity, reliability, and validity. Am J Psychiatry 1999;156:1944-50.
Gonzalez-Burgos G, Lewis DA. NMDA receptor hypofunction, parvalbumin-positive neurons, and cortical gamma oscillations in schizophrenia. Schizophr Bull 2012;38:950-7.

Goodbourn PT, Bosten JM, Hogg RE, Bargary G, Lawrance-Owen AJ, Mollon JD. Do different 'magnocellular tasks' probe the same neural substrate? Proc Biol Sci 2012;279: 4263-71.

Goto N, Yoshimura R, Kakeda S, Moriya J, Hori H, Hayashi K, et al. No alterations of brain GABA after 6 months of treatment with atypical antipsychotic drugs in early-stage first-episode schizophrenia. Prog Neuropsychopharmacol Biol Psychiatry 2010;34: 1480-3.

Green MF, Nuechterlein KH, Mintz J. Backward masking in schizophrenia and mania. II. Specifying the visual channels. Arch Gen Psychiatry 1994;51:945-51.

Harris JP, Calvert JE, Leendertz JA, Phillipson OT. The influence of dopamine on spatial vision. Eye 1990;4:806-12.

Javitt DC. When doors of perception close: bottom-up models of disrupted cognition in schizophrenia. Annu Rev Clin Psychol 2009;5:249-75.

Juhász LZ, Kemény K, Linka E, Sántha J, Bartkó G. The use of RBANS test (repeatable battery for the assessment of neuropsychological status) in neurocognitive testing of patients suffering from schizophrenia and dementia. Ideggyogy Sz 2003;56:303-8

Kay SR, Fiszbein A, Opler LA. The positive and negative syndrome scale (PANSS) for schizophrenia. Schizophr Bull 1987;13:261-76

Kegeles LS, Mao X, Stanford AD, Girgis R, Ojeil N, Xu X, et al. Elevated prefrontal cortex $\gamma$-aminobutyric acid and glutamate-glutamine levels in schizophrenia measured in vivo with proton magnetic resonance spectroscopy. Arch Gen Psychiatry 2012;69: 449-59.

Kéri S, Benedek G. Visual contrast sensitivity alterations in inferred magnocellular pathways and anomalous perceptual experiences in people at high-risk for psychosis. Vis Neurosci 2007;24:183-9.

Kéri S, Benedek G. Why is vision impaired in fragile X premutation carriers? The role of fragile X mental retardation protein and potential FMR1 mRNA toxicity. Neuroscience 2012;206:183-9.

Kéri Sz, Antal A, Szekeres Gy, Szendi I, Kovács Z, Benedek Gy, et al. A szenzoros gátlási folyamatok zavara szkizofréniában II. Kapcsolat a figyelemdeficittel. Psychiatr Hung 1999;14:393-7. [Article in Hungarian].

Kéri S, Antal A, Szekeres G, Benedek G, Janka Z. Spatiotemporal visual processing in schizophrenia. J Neuropsychiatr Clin Neurosci 2002;14:190-6.

Kéri S, Kiss I, Kelemen O, Benedek G, Janka Z. Anomalous visual experiences, negative symptoms, perceptual organization and the magnocellular pathway in schizophrenia: a shared construct? Psychol Med 2005;35:1445-55.

Kéri S, Beniczky S, Kelemen O. Suppression of the P50 evoked response and neuregulin 1-induced AKT phosphorylation in first-episode schizophrenia. Am J Psychiatry 2010;167:444-50.

Kiss I, Fábián A, Benedek G, Kéri S. When doors of perception open: visual contrast sensitivity in never-medicated, first-episode schizophrenia. J Abnorm Psychol 2010;119: 586-93.

Klosterkötter J, Hellmich M, Steinmeyer EM, Schultze-Lutter F. Diagnosing schizophrenia in the initial prodromal phase. Arch Gen Psychiatry 2001;58:158-64.

Leonova A, Pokorny J, Smith VC. Spatial frequency processing in inferred PC- and MC-pathways. Vision Res 2003;43:2133-9.

Martín-Reyes M, Mendoza Quiñones R, Díaz de Villalvilla $T$, Valdés Sosa M. Perceptual/attentional anomalies in schizophrenia: a family study. Psychiatry Res 2010;176:137-42.

McKendrick AM, Badcock DR, Gurgone M. Vernier acuity is normal in migraine, whereas global form and global motion perception are not. Invest Ophthalmol Vis Sci 2006;47: 3213-9.

Mendoza Quiñones R, Martín Reyes M, Díaz de Villalvilla T, Bravo DT, Caballero Moreno A, et al. Scale for assessing perceptual anomalies. Validation of a Spanish version of the SIAPA scale in a sample of Cuban schizophrenic patients. Actas Esp Psiquiatr 2007;35: $15-9$.

Merigan WH, Maunsell JH. How parallel are the primate visual pathways? Annu Rev Neurosci 1993;16:369-402.

Mescher M, Merkle H, Kirsch J, Garwood M, Gruetter R. Simultaneous in vivo spectral editing and water suppression. NMR Biomed 1998;11:266-72.

Nassi JJ, Callaway EM. Parallel processing strategies of the primate visual system. Nat Rev Neurosci 2009;10:360-72.

Ongür D, Prescot AP, McCarthy J, Cohen BM, Renshaw PF. Elevated gamma-aminobutyric acid levels in chronic schizophrenia. Biol Psychiatry 2010;68:667-70.

Phillipson OT, Harris JP. Perceptual changes in schizophrenia: a questionnaire survey. Psychol Med 1985;15:859-66.

Pokorny J. Review: steady and pulsed pedestals, the how and why of post-receptora pathway separation. J Vis 2011:11:1-23.

Pokorny J, Smith VC. Psychophysical signatures associated with magnocellular and parvocellular pathway contrast gain. J Opt Soc Am A Opt Image Sci Vis 1997;14: 2477-86.

Randolph C, Tierney MC, Mohr E, Chase TN. The repeatable battery for the assessment of neuropsychological status (RBANS): preliminary clinical validity. J Clin Exp Neuropsychol 1998;20:310-9

Rokem A, Yoon JH, Ooms RE, Maddock RJ, Minzenberg MJ, Silver MA. Broader visual orientation tuning in patients with schizophrenia. Front Hum Neurosci 2011;5:127.

Skottun BC, Skoyles JR. Contrast sensitivity and magnocellular functioning in schizophrenia. Vision Res 2007;47:2923-33.

Skottun BC, Skoyles JR. On identifying magnocellular and parvocellular responses on the basis of contrast-response functions. Schizophr Bull 2011;37:23-6.

Slaghuis WL. Contrast sensitivity for stationary and drifting spatial frequency gratings in positive- and negative-symptom schizophrenia. J Abnorm Psychol 1998;107: 49-62. 
Szamosi A, Kelemen O, Kéri S. Hippocampal volume and the AKT signaling system in first-episode schizophrenia. J Psychiatr Res 2012;46:279-84.

Szulc A, Galinska-Skok B, Waszkiewicz N, Bibulowicz D, Konarzewska B, Tarasow E. Proton magnetic resonance spectroscopy changes after antipsychotic treatment. Curr Med Chem 2013;20:414-27.

Tayoshi S, Nakataki M, Sumitani S, Taniguchi K, Shibuya-Tayoshi S, Numata S, et al GABA concentration in schizophrenia patients and the effects of antipsychotic medication: a proton magnetic resonance spectroscopy study. Schizophr Res 2010;117:83-91.

Treutwein B. Adaptive psychophysical procedures. Vision Res 1995;35:2503-22.
Woodward ND, Purdon SE, Meltzer HY, Zald DH. A meta-analysis of neuropsychological change to clozapine, olanzapine, quetiapine, and risperidone in schizophrenia. Int J Neuropsychopharmacol 2005;8:457-72.

Woodward ND, Purdon SE, Meltzer HY, Zald DH. A meta-analysis of cognitive change with haloperidol in clinical trials of atypical antipsychotics: dose effects and comparison to practice effects. Schizophr Res 2007;89:211-24.

Yoon JH, Maddock RJ, Rokem A, Silver MA, Minzenberg MJ, Ragland JD, et al. GABA concentration is reduced in visual cortex in schizophrenia and correlates with orientation-specific surround suppression. J Neurosci 2010;30: $3777-881$ 